\title{
Rapid Quantum Dot Nanobead-mAb Probe-Based Immunochromatographic Assay for Antibody Monitoring of Trichinella spiralis Infection
}

This article was published in the following Dove Press journal: International Journal of Nanomedicine

\author{
Ning $X u$ (D) $^{\prime}$ \\ Yan Liu' \\ Yansong $\mathrm{Li}^{\prime}$ \\ Bin Tang' \\ Xiongyan Liang ${ }^{2}$ \\ Yuying Yang ${ }^{2}$ \\ Mingyuan Liu' \\ Xiaolei Liu' \\ Yu Zhou ${ }^{1,2}$ \\ 'Key Laboratory of Zoonosis Research, \\ Ministry of Education, Institute of \\ Zoonosis, College of Veterinary \\ Medicine, Jilin University, Changchun, \\ People's Republic of China; ${ }^{2}$ College of \\ Animal Sciences, Yangtze University, \\ Jingzhou, People's Republic of China
}

Correspondence: Yu Zhou

College of Animal Science, Yangtze

University, Jingzhou, People's Republic of China

Email zhouyurunye@sina.com

Xiaolei Liu

Key Laboratory of Zoonosis Research,

Ministry of Education, Institute of

Zoonosis, College of Veterinary Medicine,

jilin University, Changchun, People's

Republic of China

Email liuxlei@I63.com
Purpose: Sensitive and selective point-of-care biosensor is an urgent pursuit of serological antibody detection to control parasite pathogen. For specific, quantitative and on-site screening of Trichinella spiralis infection in livestock, a quantum dot nanobead-monoclonal antibody (QB-mAb) probe-based immunochromatographic assay (ICA) was developed by introducing a competitive sandwich strategy (QB-CICA).

Methods: In the QB-CICA, QB-mAb probes competed with serum antibody for a particular epitope, followed by immunocomplexes binding to capture antibody on the test line. With the accumulation of target antibody, captured probes served as signal elements for fluorescent readout in a "turn off" mode, along with the fluorescence gradually weakened. The sensitivity and standard calibration curve of the QB-CICA were quantified using swine sera as negative control $(n=200)$ and artificial infected swine sera $(n=80)$ compared with a commercial ELISA kit. Besides, Trichinella spiralis-antibody targeting test ability of the QB-CICA, instead of other parasites or viruses antibodies $(n=10)$, was evaluated.

Results: The QB-CICA exhibited a good linear range, a low detection limit of $189.92 \mathrm{ng} \mathrm{mL}^{-1}$ and $100 \%$ selectivity that was higher than commercial ELISA kit (90\%), as well as the same serological positive rate $(100 \%)$ with commercial ELISA kit in different infection dose models. Conclusion: Taking advantage of its simplicity, short response time (25 min), sensitivity and specificity, the proposed QB-CICA has potential applications for parasite-related antibody monitoring in food safety and clinical diagnosis fields.

Keywords: rapid serological antibody test, competitive sandwich immunochromatographic assay, quantum dot nanobead, Trichinella spiralis

\section{Introduction}

Rapid serological antibody test of pathogen infection is important for on-site initial screening, ${ }^{1,2}$ epidemiological surveys ${ }^{3}$ and the origin of new epidemic diseases. ${ }^{4,5}$ In particular, a quantification test for target antibody can determine the protective power of vaccines $^{6,7}$ and determine whether the infected host is in active or recovery phase. ${ }^{8}$ Methods for antibody test of particular epitope, using monoclonal antibody, are necessary in many cases, including distinguishing infections due to pathogens of different subtypes with similar genomes, ${ }^{9}$ differential diagnosis of naturally infected versus vaccinated hosts $^{10,11}$ and elimination of cross-reactivity. ${ }^{12}$ Cross-reactivity is a major problem in the sera-diagnosis of parasite infection due to a mixture type antigen used. ${ }^{13,14}$ However, methods for specific and quantitative detection of parasite-related antibody are limited to enzyme-linked immunosorbent assay (ELISA). 
Immunochromatographic assay (ICA) is a rapid, userfriendly, portable and widely used biosensor for point-ofcare test (POCT) of pathogen infection. ${ }^{15,16}$ Traditional ICAs employ gold nanoparticles (AuNPs) and provide a binary yes/no answer that corresponds to the presence if the concentration of target antibody is over or under a specific cut-off level. ${ }^{17-20}$ Disturbed red optical intensity of AuNPs in complex biological body fluid condition and reduced colloidal stability in harsh conditions, such as in salt solutions, restrict their further applications in traditional ICAs for serum antibody test. Currently, quantum dot nanobeads (QBs) with resistance to matrix interference are used to improve the sensitivity and stability of ICAs, because of their controllable fluorescent emission wavelengths, narrow peaks and more intense fluorescence signals than the original quantum dots. ${ }^{21-23}$

Trichinella spiralis (T. spiralis) is a food-borne zoonotic parasite causing a large number of human infections annually ${ }^{24}$ via consumption of under-cooked infectious meat. According to recommendations of the International Commission on Trichinellosis (ICT), serological testing is a prerequisite for infection monitoring in preslaughter care of livestock to ensure food safety. ${ }^{25}$ Excretory-secretory (ES) products, a mixture type antigen used in sera-diagnosis, have problems in crossreaction and reproducibility. ${ }^{13,26,27}$ The most widely used T. spiralis antibody detection method is ELISA employing ES products, which is sensitive but is not specific and timeconsuming (Table S1). Although two ICAs based on ES products and AuNPs have been reported, ${ }^{17,18}$ the cross-reaction problem remains unresolved with sensitivity reduced (Table

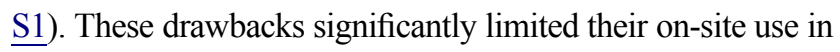
surveillance of herds. Currently, an urgent pursuit of serological testing is a sensitive and specific POCT to control the parasite. A cystatin-like protein (CLP) is an antigenic component of ES products, an ELISA based on which has been preliminarily evaluated for sera-diagnosis. ${ }^{28}$ The improvement of serological assays employing particular epitope of CLP appears to be a promising strategy.

QB-based ICAs have been reported for detection of small chemical molecules ${ }^{21,23}$ and viral pathogen with the sandwich assay. ${ }^{22}$ In this study, a novel competitive sandwich format-based ICA was developed for detection of serum antibody that compete with probes (QB-monoclonal antibody, QB-mAb) for one epitope. Followed by immunocomplexes binding to capture antibody, a sandwich compound was formed on a test zone. The captured probes serve as signal elements for fluorescent readout in a "turn off" mode, resulting in short response time, quantification and specificity. The QB-mAb probes were first used to develop a competitive sandwich ICA (QB-CICA) for sensitive and accurate sera-diagnosis of swine infected by $T$. spiralis at various stages and levels.

\section{Experiments \\ Parasite and Sera}

A pooled serum sample from 30 Trichinella-free pigs served as the negative control serum, and a pooled serum sample from 3 pigs infected with 10,000 larvae at 120 days post-infection (dpi) served as the positive control serum. Two hundred negative sera were used to determine the cut-off value. CLP antibody (CLP Ab) was purified by saturated ammonium sulfate solution ${ }^{29}$ from the recombinant CLP (rCLP)-immunized pig, whose preimmunized serum served as the source of background in calibration curves. Sera from pigs infected with 10,000 larvae were collected at 7, 11, 17, 19, 21, 25, 30, 35, 45, 60, 90 and $120 \mathrm{dpi}$, and were used in antibody kinetics.

Sera from Clonorchis sinensis, Toxoplasma gondii, Taenia asiatica and Taenia solium experimentally infections served as other parasite-infected samples. Six sera from scale livestock farm served as virus vaccineimmunized samples, these virus vaccines included porcine pseudorabies virus, porcine reproductive and respiratory syndrome virus, porcine circovirus, classical swine fever virus and foot-and-mouth disease virus.

Sera from pigs infected with 200, 400, 800 and 1000 larvae were collected at $120 \mathrm{dpi}$. All corresponding diaphragm tissues were detected with artificial digestion. ${ }^{30}$ Animal welfare and experimental designs were performed strictly in accordance with the guide for the care and use of laboratory animals (Care and Animals, 2011). All animal experiments in this study were approved by the Ethical Committee of Jilin University affiliated with the Provincial Animal Health Committee, China (ethical clearance number IZ-2009-08).

\section{Reagents and Instruments}

The $\mathrm{mAb}$ recognized the epitope HEALFSSDLKQESGV and rCLP antigens were prepared in our previous study. ${ }^{28}$ The $\mathrm{mAb}$ characterization (Figure $\mathrm{S} 1$ ), rabbit anti-CLP Ab production (Figures $\mathrm{S} 2$ and $\underline{\mathrm{S} 3}$ ) and CLP Ab production using rCLPimmunized pig (Figure S4) were described in detail in the Supporting Information. COOH-modified CdSe/ZnS QBs $\left(10 \mathrm{mg} \mathrm{mL} \mathrm{m}^{-1}\right)$ were purchased from Shanghai Kundao Biotech Co., Ltd. (Shanghai, China). A commercial ELISA 
kit employing ES products was obtained from Qiagen (cat. No. 273501, Germany). Nitrocellulose (NC) membranes were purchased from GE Healthcare (Wisconsin, USA). Sample pads, absorbent pads and backing cards were obtained from Shanghai Jieyi Biotechnology Co., Ltd. (Shanghai, China). All other chemicals were of analytical reagent grade. A transmission electron microscope (TEM, H-7650) was purchased from Hitachi (Tokyo, Japan). A portable fluorescence strip reader was obtained from Nanjing Microdetection Biological Technology Co., Ltd. (Nanjing, China).

Buffer solutions were prepared as follows: reaction buffer: $30 \mathrm{mM}$ 4-(2-Hydroxyethyl)piperazine-1-ethanesulfonic acid (HEPES) (pH 7.0); activating buffer: $10 \quad \mathrm{mM}$ 1-(3-Dimethylaminopropyl)-3-ethylcarbodiimide (EDC) and $30 \mathrm{mM}$ HEPES ( $\mathrm{pH} 7.0$ ); blocking buffer: 1.5\% bovine serum albumin (BSA) (w/v) and $30 \mathrm{mM} \mathrm{HEPES} \mathrm{(pH} \mathrm{7.0);}$ storage buffer: $50 \mathrm{mM}$ Tris ( $\mathrm{pH} 7.2)$; sample pad treatment buffer: $0.2 \%$ BSA (w/v), $0.05 \%$ Tween $20(\mathrm{v} / \mathrm{v})$ and 0.01 $\mathrm{M}$ phosphate buffer ( $\mathrm{pH} 7.4)$. All solutions were freshly prepared before use.

\section{Functionalization of QB with $\mathrm{mAb}$}

QB-mAb probes were prepared as follows: ${ }^{31} \mathrm{QB}$ at $10 \mu \mathrm{L}$ were washed with $40 \mu \mathrm{L}$ of reaction buffer under centrifugation $\left(10,000 \times g, 4{ }^{\circ} \mathrm{C}, 30 \mathrm{~min}\right)$, with nanobeads dispersed into $60 \mu \mathrm{L}$ of activating buffer and incubated at $25{ }^{\circ} \mathrm{C}$ for $1 \mathrm{~h}$. After centrifugation, the sediment was dissolved in $50 \mu \mathrm{L}$ of reaction buffer followed by incubation with $15 \mu \mathrm{g}$ of $\mathrm{mAb}$ for $1 \mathrm{~h}$ at $25^{\circ} \mathrm{C}$. After centrifugation, the sediment was dissolved in $50 \mu \mathrm{L}$ of blocking buffer and incubated at $25^{\circ} \mathrm{C}$ for $1 \mathrm{~h}$. Then, the obtained conjugates were dissolved in $100 \mu \mathrm{L}$ of storage buffer. The cross-linking principle is shown in Figure 1A.

\section{Fabrication of the QB-CICA}

Sample pads were treated with sample pad treatment buffer and dried at $37{ }^{\circ} \mathrm{C}$ overnight. Rabbit anti-CLP Ab $(3.0 \mathrm{mg}$ $\left.\mathrm{mL}^{-1}\right)$ and rabbit anti-mouse $\operatorname{IgG}\left(0.5 \mathrm{mg} \mathrm{mL}^{-1}\right)$ were spotted onto NC membranes as the test (T) and control (C) lines respectively, and then dried at $37^{\circ} \mathrm{C}$ for $2 \mathrm{~h}$. The sample pad, NC membrane and absorption pad were attached to backing card $(80 \mathrm{~mm} \times 30 \mathrm{~mm})$ and cut into $4 \mathrm{~mm}$ wide strips.

\section{Immunoassay Procedure of the QB-CICA}

The concentration of the mAb labeled with $\mathrm{QB}$, the dilution factor of serum, the concentration of rCLP antigens in the reaction solution and the concentration of capture antibody on the T-line were considered important factors that affected the sensitivity of the QB-CICA. The optimization of the QB-CICA parameters was based on the signal

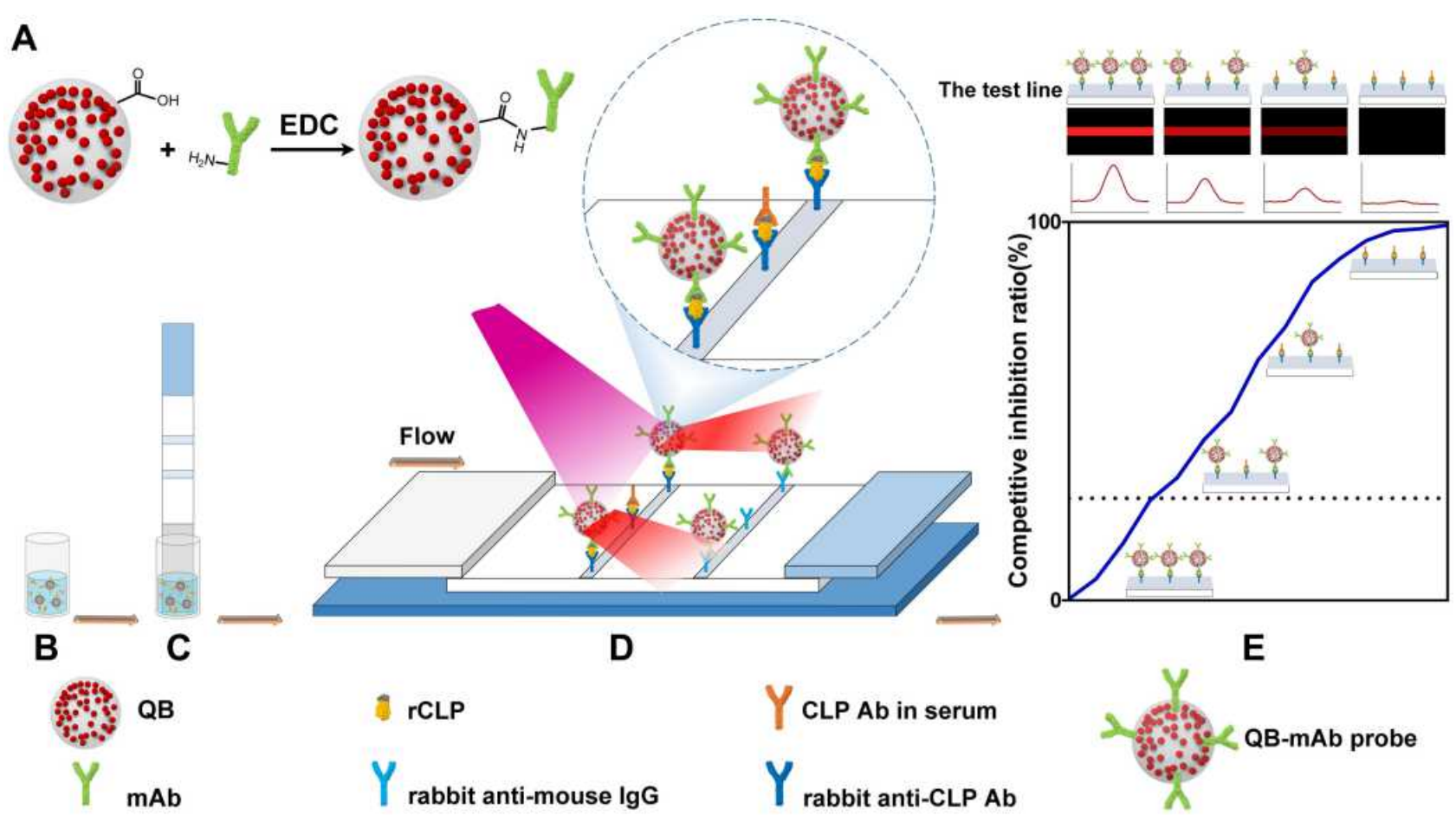

Figure I Schematic diagram of the QB-CICA. Principle of the cross-linking (A); mixing of rCLP, serum and QB-mAb probes (B); the strip was immersed in the mixture solution (C); capture of immunocomplexes by rabbit anti-CLP Ab on the T-line (D); imaging and interpretation of results (E). 
intensity of the T-line and the competitive inhibition (PI) ratio of the positive control serum, which was carried out at room temperature in the dipstick format. ${ }^{32}$ As shown in Figure 1, QB-mAb probes were incubated with $50 \mu \mathrm{L}$ of swine serum and $50 \mu \mathrm{L}$ of reaction solution $(0.9 \% \mathrm{NaCl}$ solution $(\mathrm{w} / \mathrm{v})$ containing $0.05 \mu \mathrm{g} \mathrm{rCLP})$ in ELISA wells for $10 \mathrm{~min}$. The strip was inserted into the mixture for 5 min and left flat for $10 \mathrm{~min}$, followed by signal recordings using the portable reader.

\section{Cut-Off Value of the QB-CICA}

The result of each serum sample was expressed as the PI ratio that was obtained by $\left(1-\mathrm{B} / \mathrm{B}_{\mathrm{NC}}\right) \times 100 \% .{ }^{21} \mathrm{~B}_{\mathrm{NC}}$ and $B$ were fluorescence intensities of the T-line of negative control serum and sample serum, respectively. The cut-off value was calculated based on the result mean of 200 negative sera plus two standard deviations. ${ }^{7}$

\section{Validation of the QB-CICA}

\section{Establishment of the Standard Calibration Curve}

The CLP Ab was diluted using preimmunized serum of the rCLP-immunized pig at concentrations from 100 to 850 $\mathrm{ng} \mathrm{mL}^{-1}$. The standard curves were generated by plotting the PI ratio against the concentration of CLP Ab. The limit of detection (LOD) was defined as the concentration of CLP Ab that caused a PI ratio exceeding the cut-off value. The results of QB-CICA were compared with those obtained from commercial ELISA kit, the signal-topositive (S/P) ratio and cut-off value of ELISA were calculated according to the manufacturer's instructions.

\section{Analysis of Antibody Kinetics Using T. spiralis Infected Sera}

Antibody kinetics of $T$. spiralis infection at various stages were determined using QB-CICA and commercial ELISA kit. Seroconversion was defined as the time point when the concentration of target antibody caused a PI ratio that exceeded the cut-off value.

\section{Specificity Testing}

The specificity of the QB-CICA was evaluated using ten sera (four samples were from other parasite-infected pigs, six samples were from virus vaccine-immunized pigs). And the results were compared with those obtained from commercial ELISA kit.

\section{Accuracy Testing}

The accuracy of the QB-CICA was evaluated by analyzing sera from swine infected with different doses of $T$. spiralis.
Each dose group included three pigs. The results were compared with those obtained by commercial ELISA kit using the same serum samples. And corresponding diaphragm tissues were detected with artificial digestion.

\section{Results and Discussion \\ Principle of the QB-CICA}

The main format used in ICAs to detect pathogenassociated antibodies in sera was the indirect assay or the sandwich assay. ${ }^{1,2,15,17}$ So far, assays based on the competitive sandwich format used for measuring antibody have focused only on ELISAs. ${ }^{6,33,34}$ In this study, principle of the QB-CICA was based on competitive binding between the analyte (CLP Ab, in serum) and QB-mAb probes (as competitors) to a limited amount of antigen (one epitope of rCLP). Then, immunocomplexes formed by QB-mAb and rCLP bound to an adequate amount of capture antibody (rabbit anti-CLP Ab) on the T-line. The excess probes continued to migrate along the strip and were captured on the C-line, ensuring the validity of the biosensor (Figure 1). The more analytes in the sample, the less immunocomplexes containing QB-mAb would be captured on the T-line, which led to a decrease in the fluorescence signal. When the PI ratio exceeds the cutoff value obtained by testing numbers of known negative sera, the serological antibody test is positive (Figure 1E).

\section{Characterization of the QB-mAb Probes}

As shown in Figure 2, TEM images indicated that quantum dots were nearly monodisperse with dot-shape in all nanobeads. The protein halo around QBs can be observed (Figure 2B), showing that the $\mathrm{mAb}$ was successfully labeled with naked QBs. Compared with bare QBs, the average size ${ }^{21}$ of QB-mAb probes was increased from 103 $\mathrm{nm}$ to $108 \mathrm{~nm}$ (Figure 2C). QB-mAb probes as well as QBs exhibited narrow emission peaks at $620 \mathrm{~nm}$ (Figure 2D) that was beneficial to minimize background interference of serum sample. Compared with QBs diluted directly into equal volume solution, fluorescence intensity of QB-mAb probes solution slightly reduced after functionalization (Figure 2D), which increased approximately linearly with increasing concentration of used QBs that coupled with $15 \mu \mathrm{g} \mathrm{mAb}$ (Figure 2E). According to the procedure of ELISA employing rCLP antigens in our previous study, ${ }^{28}$ the standard curve of binding rate of QB$\mathrm{mAb}$ probes to rCLP antigens was obtained (Figure 2F). 

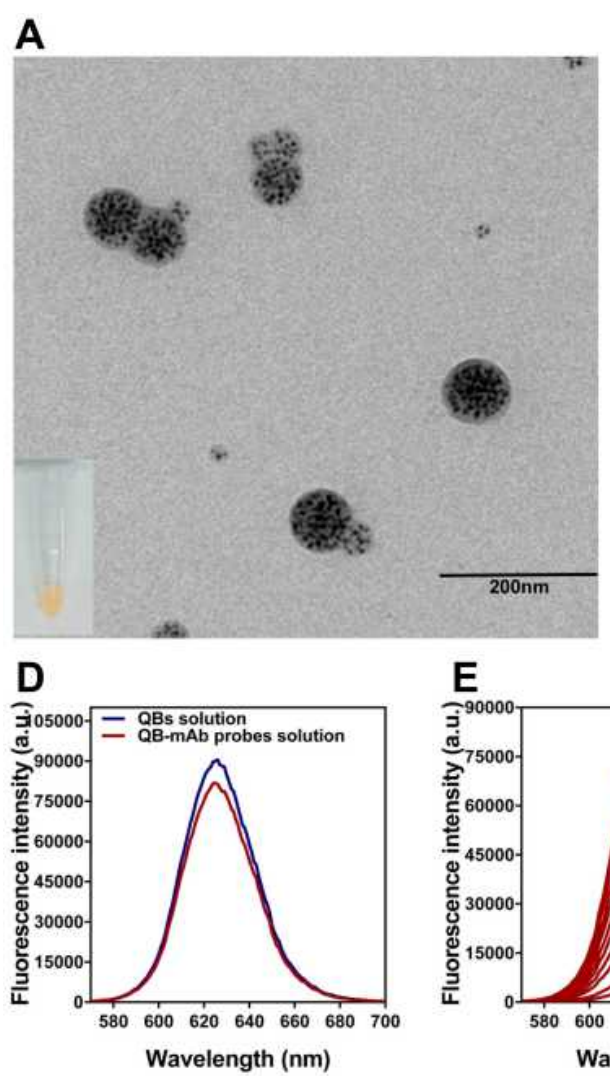

B

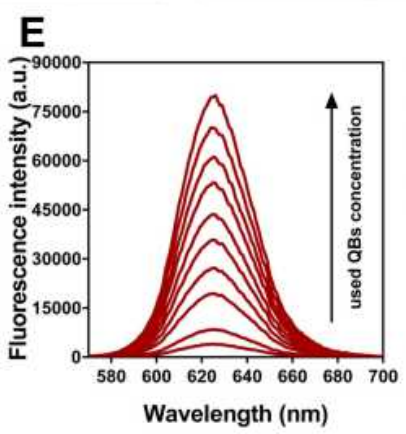

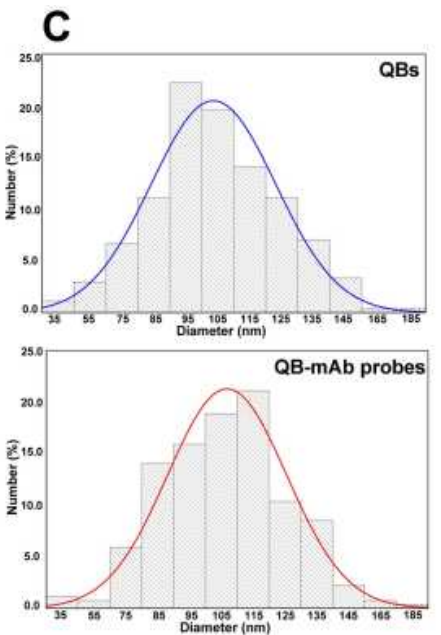

$\mathbf{F}$

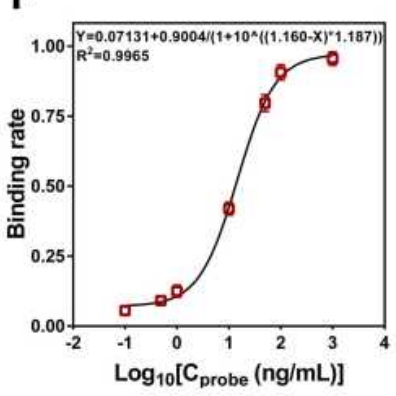

Figure 2 QB-mAb probes characterization. TEM images of QBs (A) and QB-mAb probes (showing the protein halo) (B). The diameter dimensions of QBs and QB-mAb probes $(\mathbf{C})$. Fluorescence spectra of QB-mAb probes solution compared with QBs diluted directly into equal volume solution excited by $365 \mathrm{~nm}$ (D), and fluorescence intensity of QB-mAb probes solution prepared with increasing concentrations of QBs (E). The standard curve of binding rate against concentration of $Q B-m A b$ probes by ELISA employing $r C L P$ antigens $(\mathbf{F})$. The binding rate is defined as $B / B_{0}$, where $B$ is the response fluorescence intensity of probes with different concentrations, and $B_{0}$ is the maximal response value.

The results showed that QB-mAb probes could effectively bind to rCLP antigens.

\section{Optimization of the QB-CICA Parameters}

As shown in Figure 3A, the T-line signal of negative control serum continuous increased with increasing $\mathrm{mAb}$ concentration, which reached the maximum value at 150

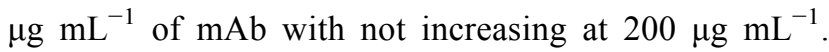
However, the T-line signal of positive control serum increased suddenly when the concentration of $\mathrm{mAb}$ was $200 \mu \mathrm{g} \mathrm{mL} L^{-1}$, as a result, positive control serum presented bad activities in competition with QB-mAb probes for the available epitopes of rCLP antigens, thereby leading to a decrease in the PI ratio. According to the criterion with the highest PI ratio ${ }^{21}$, $150.00 \mu \mathrm{g} \mathrm{mL}^{-1}$ of the mAb was chosen as the optimal concentration for coupling with $100 \mu \mathrm{L}$ of $\mathrm{QB}$, with approximately $0.015 \mu \mathrm{g}$ of the $\mathrm{mAb}$ used on each strip. Similarly, the optimal ratio of serum sample and the reaction solution was observed at a ratio of $1: 1$ (Figure 3B). And the optimal concentration of rCLP antigens was chosen as $1.00 \mu \mathrm{g} \mathrm{mL}^{-1}$ (Figure $3 \mathrm{C}$ ). Besides, $3.00 \mathrm{mg} \mathrm{mL}$ of capture antibody was regarded as the optimal concentration to produce the highest PI ratio (Figure 3D). Moreover, the fluorescence intensity of QB-mAb probes were basically unchanged over six months at $4{ }^{\circ} \mathrm{C}$ (Figure 3E), with the fluorescent signal of strips not weakened using the negative control serum (Figure 3F). Other parameters including the $\mathrm{pH} /$ time in cross-linking reaction, time of each step and stability in $\mathrm{NaCl}$ solutions as well as hemolytic samples were shown in Figures S5 and $\underline{\text { S6 }}$.

\section{Analytical Performance of the QB-CICA}

The cut-off value of QB-CICA was determined to be $50 \%$ using 200 known negative sera (Figure S7). As the amount of CLP Ab increased, the fluorescence intensity of the strip decreased and the curve obtained by the strip reader 


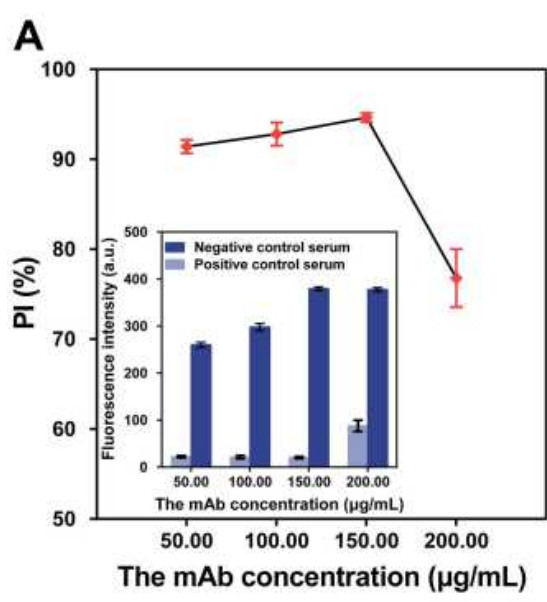

D

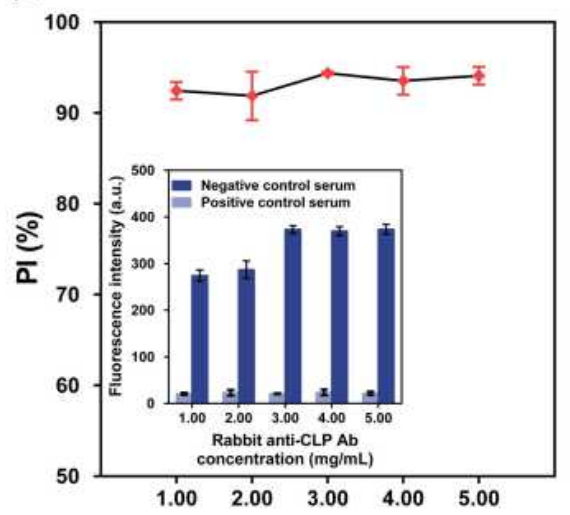

Rabbit anti-CLP Ab concentration $(\mathrm{mg} / \mathrm{mL})$
B

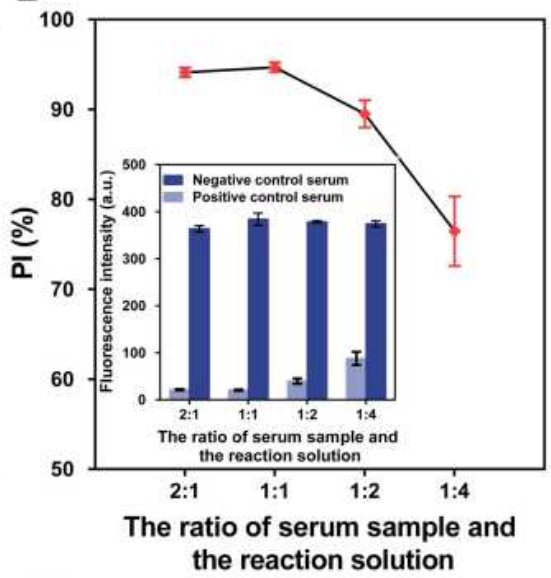

E

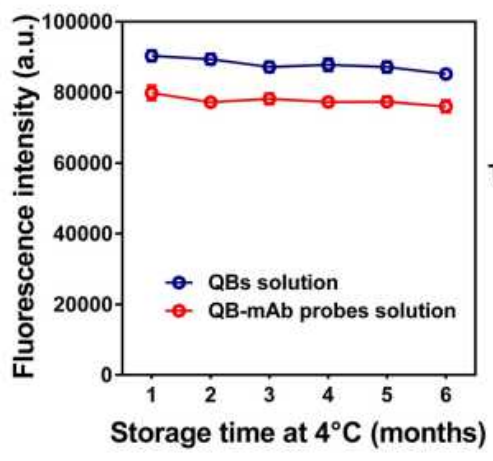

C

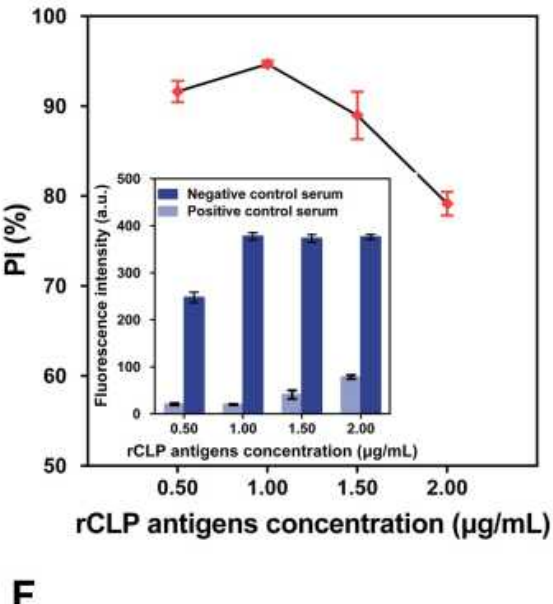

$\mathbf{F}$

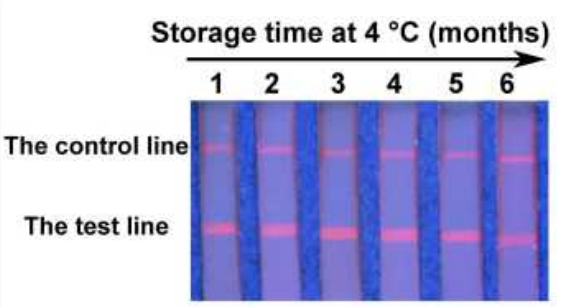

Figure 3 Optimization of the QB-CICA parameters. Optimizing the concentration of the mAb labeled with QB (A), dilution factor of serum (B), concentration of rCLP antigens in the reaction solution (C) and concentration of rabbit anti-CLP Ab on the test line (D). (Inset: fluorescence intensity of the test line recorded by the strip reader according to the area under peak). The fluorescence intensity of QB-mAb probes (E) and images of strips using negative serum (F) at different storage time. Results are expressed as the mean \pm SD of 3 tests.

became flat (Figure 4A). A good linear correlation was obtained, and the LOD was $189.92 \mathrm{ng} \mathrm{mL}^{-1}$ calculated from the linear function and the cut-off value (Figure 4B), nearly the same as that of commercial ELISA kit (Figure S8A).

To evaluate the analytical performance of QB-CICA in real infection samples, experimental infection models were used to plot kinetics of PI ratios. For the QBCICA, there was an increase in the immune response following seroconversion until $21 \mathrm{dpi}$ for $2 / 3$ pigs (Figure 4C). Besides, a 4-day delay for only one pig in seroconversion occurred compared to commercial ELISA kit (Figure S8B). Considering the complexity of the interaction between parasites and host immune system at various stages, the early seroconversion and continuous serological positive illustrated that the QBCICA was comparable sensitive and stable to monitoring changes of target antibody.

\section{Selectivity of the QB-CICA}

All PI ratios of 10 serum samples obtained by QB-CICA were lower than $35 \%$ while a false positive result occurred in ELISA (Figure 4D, S9), indicating that QB-CICA can specifically detect $T$. spiralis antibody instead of other parasites antibodies or viruses antibodies induced by vaccines. Moreover, ES products cross-reacted with Clonorchis Ab (Figure 4D, S9), which was consistent with previous reports. ${ }^{13,27}$ These results demonstrated that the developed QB-CICA has better selectivity than ELISA employing mixed antigens in our study. 
A

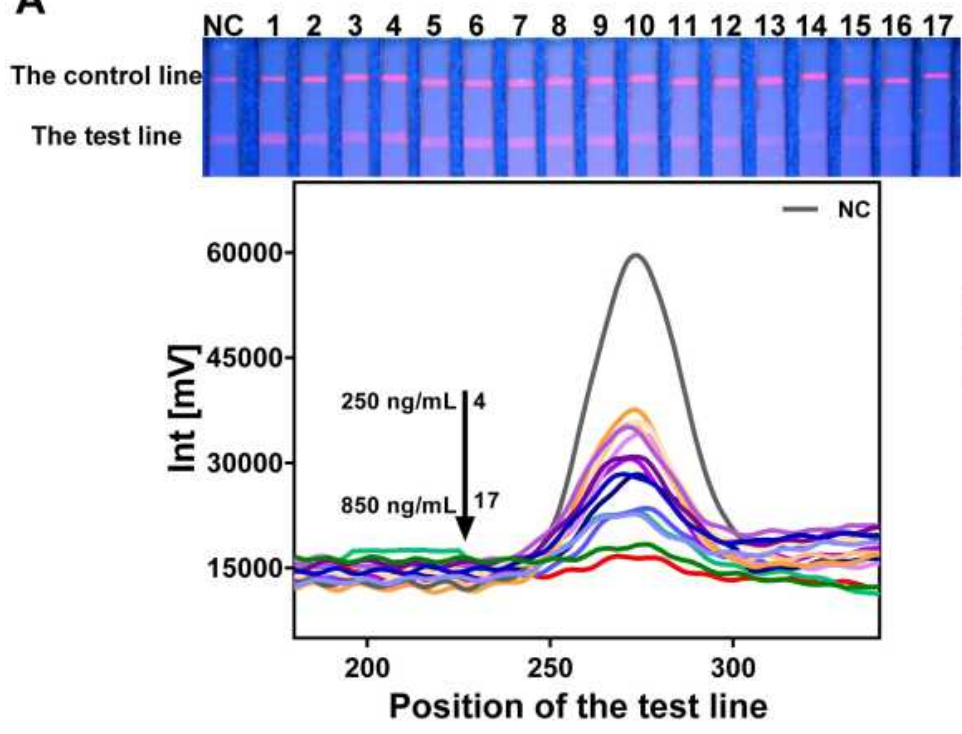

C

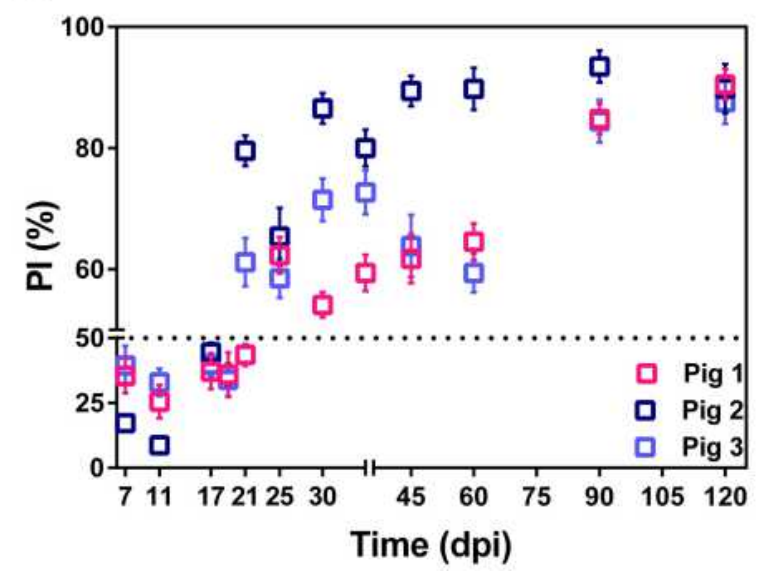

B

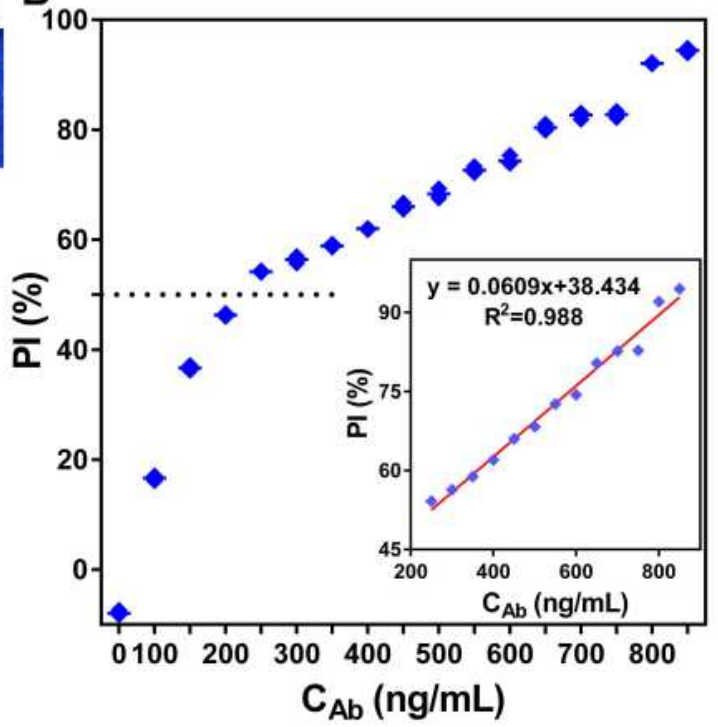

D

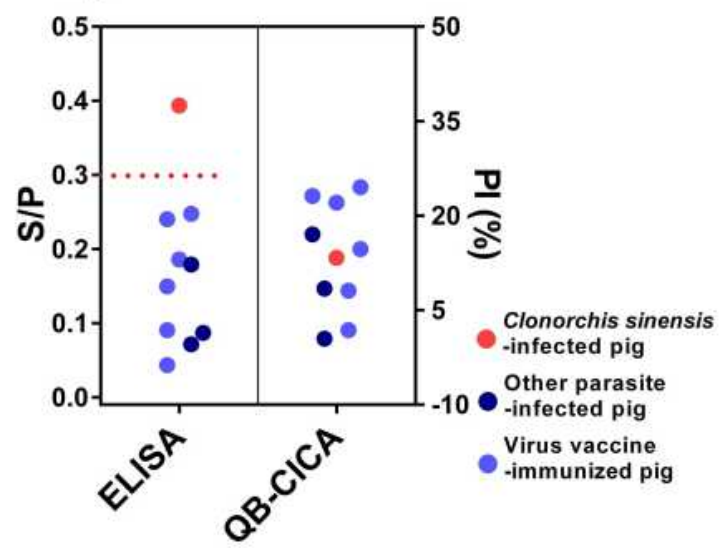

Figure 4 Analytical performance of the QB-ClCA. Images and fluorescence curves of strips at different concentrations of CLP Ab from I00 to $850 \mathrm{ng} \mathrm{mL}^{-1}$ (A); calibration curve of CLP Ab (B); kinetics of PI ratios in the QB-CICA using experimental infection serum samples (C); specificity testing in swine serum (D). Results are means of 3 tests. Fabrication of calibration curve and kinetics of PI ratios are expressed as the mean \pm SD.

\section{Accuracy of the QB-CICA}

The proposed QB-CICA was compared with commercial ELISA kit using sera of different dose infection models. As the larvae of $T$. spiralis infection increased, the fluorescence intensity on the T-line weakened (Figure 5A), and the curve flattened out (Figure 5B). The QB-CICA had a $100 \%$ positive detection rate (12/ 12 pigs) at different infection levels, with the same rate obtained by ELISA (Figure 5C). All corresponding diaphragm tissues were examined to estimate the larvae burdens (Table S2). In light infection level (200 larvae group), $3 / 3$ pigs were positive by QB-CICA compared to $2 / 3$ pigs positive by artificial digestion (Table S2), showing that the proposed QB-CICA is a sensitive and accurate tool for screening of $T$. spiralis infection in pig serum samples. Compared to other current serological antibody test methods (Table 1), the QB-CICA has many advantages, including a higher specificity, portability and the ability to produce results rapidly, indicating that QB-CICA is suited for rapid screening of $T$. spiralis infection. Moreover, this novel competitive sandwich QB-CICA also provides useful reference information for POCT strategies in pathogen infection sera-diagnosis (Table S3). 
A

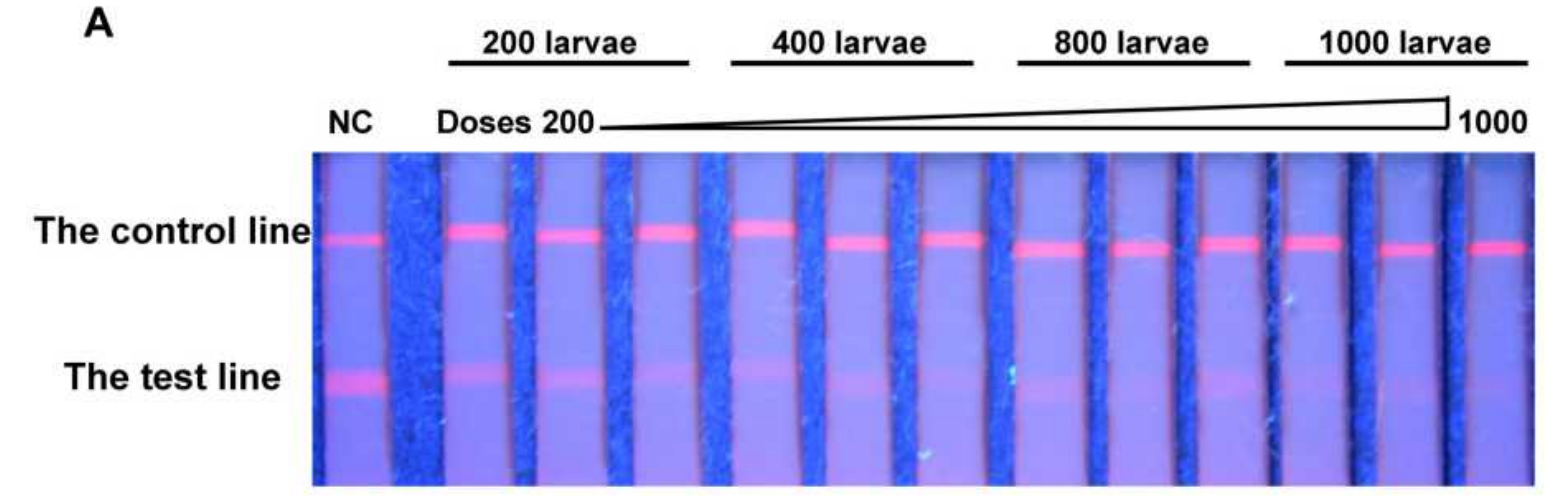

B

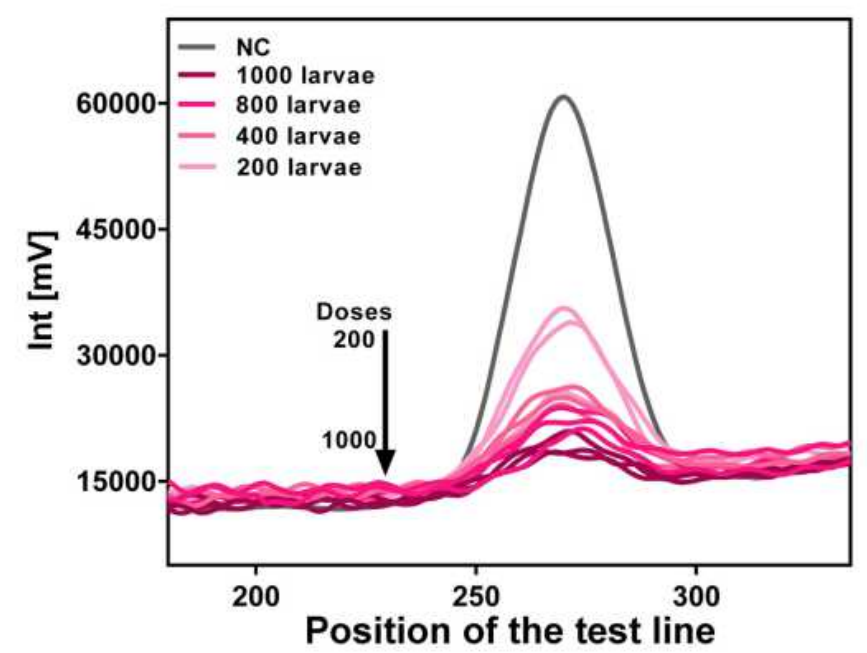

C

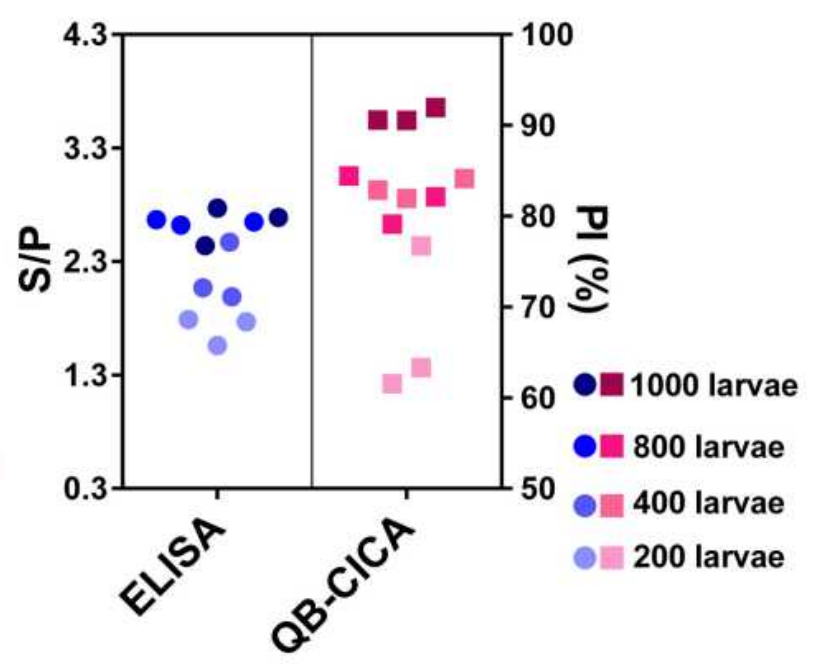

Figure 5 Accuracy of the QB-CICA. Images (A) and fluorescence curves (B) of strips in different doses of T. spiralis infection models from 200 to 1000 larvae; accuracy of the QB-CICA in swine serum at different infection levels $(\mathbf{C})$. Results are means of 3 tests.

\section{Conclusion}

A competitive sandwich QB-CICA was developed based on a novel QB-mAb probe, which was systematically evaluated for $T$. spiralis antibody test using infection models. The QB-CICA exhibited short response time (25 min), high sensitivity with a good linear range, and better selectivity than commercial ELISA kit. Therefore, the newly developed QB-CICA is recommended for rapid on-site detection of $T$. spiralis antibody in herds to ensure food safety and other POCT applications for pathogen infection.

Table I Comparison Between the Developed QB-CICA and Other Methods for Serological Antibody Test of T. spiralis Infection

\begin{tabular}{|c|c|c|c|c|c|c|c|c|}
\hline Method & $\begin{array}{l}\text { Detection } \\
\text { Antigens }\end{array}$ & Cross-Reaction & $\begin{array}{l}\text { Quantitative } \\
\text { Capability }\end{array}$ & LOD & Instrument & Portability & Time & Ref. \\
\hline ELISA & ES & $\begin{array}{l}\text { Other parasite infections; } \\
\text { nonparasite infections; }\end{array}$ & Yes & $\begin{array}{l}174.95 \\
\mathrm{ng} / \mathrm{mL}\end{array}$ & $\begin{array}{l}\text { Microplate } \\
\text { reader }\end{array}$ & Bulky & $\begin{array}{l}>1.5 \\
\mathrm{~h}\end{array}$ & $\begin{array}{l}{[13,26,27]} \\
\text { This work }\end{array}$ \\
\hline $\begin{array}{l}\text { AuNPs- } \\
\text { ICA }\end{array}$ & & noninfective pathologies & No & $-{ }^{\mathrm{b}}$ & Naked eyes & Portable & $\begin{array}{l}\approx 15 \\
\min \end{array}$ & {$[17,18]$} \\
\hline $\begin{array}{l}\text { QB- } \\
\text { CICA }\end{array}$ & rCLP & None $^{a}$ & Yes & $\begin{array}{l}189.92 \\
\mathrm{ng} / \mathrm{mL}\end{array}$ & $\begin{array}{l}\text { Fluorescence } \\
\text { ICA reader }\end{array}$ & Portable & $\begin{array}{l}\approx 25 \\
\min \end{array}$ & This work \\
\hline
\end{tabular}

Notes: ${ }^{a}$ Limited serum samples in this work. ${ }^{b}$ Not tested. 


\section{Abbreviations}

T. spiralis, Trichinella spiralis; QB, quantum dot nanobead; QB-mAb probe, quantum dot nanobead-monoclonal antibody probe; ICA, immunochromatographic assay; QBCICA, a competitive sandwich immunochromatographic assay based on the QB-mAb probe; ES products, Excretorysecretory products; CLP, cystatin-like protein; rCLP, recombinant cystatin-like protein; CLP Ab, cystatin-like protein antibody; dpi, days post-infection; PI ratio, competitive inhibition ratio; $\mathrm{S} / \mathrm{P}$ ratio, signal-to-positive ratio; LOD, the limit of detection; POCT, point-of-care test.

\section{Funding}

This study was supported by the National Key Research and Development Program of China (2017YFD0501302, 2017YFC1601206); the National Natural Science Foundation of China (NO. 31871888, 31520103916, 31872467); Guangdong innovation and Entrepreneurial Research Team Program (NO. 2014ZT05S123); Jilin Provincial Science and Technology Development Project (20180520042JH); Natural science research project jointly built by Jilin Province and Jilin University (SXGJSF2017-6); and Program for JLU Science and Technology Innovative Research Team.

\section{Disclosure}

None of the authors has any financial or personal relationship with other people or organisations that could inappropriately influence or bias the work reported in this paper.

\section{References}

1. Begeman IJ, Lykins J, Zhou Y, et al. Point-of-care testing for Toxoplasma gondii $\mathrm{IgG} / \mathrm{IgM}$ using Toxoplasma ICT IgG-IgM test with sera from the United States and implications for developing countries. PLoS Negl Trop Dis. 2017;11(6):e5670. doi:10.1371/journal.pntd.0005670

2. Chen Z, Zhang Z, Zhai X, et al. Rapid and sensitive detection of anti-SARS-CoV-2 IgG using lanthanide-doped nanoparticles-based lateral flow immunoassay. Anal Chem. 2020;92(10):7226-7231. doi:10.1021/acs.analchem.0c00784

3. Cruz HM, de Paula VS, Cruz JCM, et al. Evaluation of accuracy of hepatitis $\mathrm{B}$ virus antigen and antibody detection and relationship between epidemiological factors using dried blood spot. $J$ Virol Methods. 2020;277:113798. doi:10.1016/j.jviromet.2019.113798

4. Tu C, Crameri G, Kong X, et al. Antibodies to SARS coronavirus in civets. Emerg Infect Dis. 2004;10(12):2244-2248. doi:10.3201/ eid1012.040520

5. Xiao K, Zhai J, Feng Y, et al. Isolation of SARS-CoV-2-related coronavirus from Malayan pangolins. Nature. 2020;583 (7815):286-289. doi:10.1038/s41586-020-2313-x

6. Periolo OH, Seki C, Grigera PR, et al. Large-scale use of liquid-phase blocking sandwich ELISA for the evaluation of protective immunity against aphthovirus in cattle vaccinated with oil-adjuvanted vaccines in Argentina. Vaccine. 1993;11(7):754-760. doi:10.1016/0264-410X (93) $90261-U$
7. Wang Q, Ju H, Li Y, et al. Development and evaluation of a competitive ELISA using a monoclonal antibody for antibody detection after goose parvovirus virus-like particles (VLPs) and vaccine immunization in goose sera. $J$ Virol Methods. 2014;209:69-75. doi:10.1016/j.jviromet.2014.08.021

8. Beck C, Lowenski S, Durand B, et al. Improved reliability of serological tools for the diagnosis of West Nile fever in horses within Europe. PLoS Negl Trop Dis. 2017;11(9):e5936. doi:10.1371/journal. pntd.0005936

9. Moreno A, Lelli D, Lavazza A, et al. MAb-based competitive ELISA for the detection of antibodies against influenza D virus. Transbound Emerg Dis. 2018;66:268-276. doi:10.1111/ tbed.13012

10. Oem JK, Chang BS, Joo HD, et al. Development of an epitope-blocking-enzyme-linked immunosorbent assay to differentiate between animals infected with and vaccinated against foot-andmouth disease virus. J Virol Methods. 2007;142(1-2):174-181. doi:10.1016/j.jviromet.2007.01.025

11. Uttenthal $\AA$, Parida S, Rasmussen TB, et al. Strategies for differentiating infection in vaccinated animals (DIVA) for foot-andmouth disease, classical swine fever and avian influenza. Expert Rev Vaccines. 2014;9(1):73-87. doi:10.1586/erv.09.130

12. Gnjatovic M, Gruden-Movsesijan A, Miladinovic-Tasic N, et al. A competitive enzyme-linked immunosorbent assay for rapid detection of antibodies against Trichinella spiralis and T. britovi- one test for humans and swine. J Helminthol. 2017;93(1):33-41. doi:10.1017/ S0022149X17001092

13. Gómez-Morales MA, Ludovisi A, Amati M, et al. Validation of an enzyme-linked immunosorbent assay for diagnosis of human trichinellosis. Clin Vaccine Immunol. 2008;15(11):1723-1729. doi:10.1128/CVI.00257-08

14. Javadi Mamaghani A, Fathollahi A, Spotin A, et al. Candidate antigenic epitopes for vaccination and diagnosis strategies of Toxoplasma gondii infection: a review. Microb Pathog. 2019;137:103788. doi:10.1016/j.micpath.2019.103788

15. Parolo C, Merkoci A. Paper-based nanobiosensors for diagnostics. Chem Soc Rev. 2013;42(2):450-457. doi:10.1039/c2cs35255a

16. Yeo S, Cuc BT, Kim S, et al. Rapid detection of avian influenza A virus by immunochromatographic test using a novel fluorescent dye. Biosens Bioelectron. 2017;94:677-685. doi:10.1016/j. bios.2017.03.068

17. Fu BQ, Li WH, Gai WY, et al. Detection of anti-Trichinella antibodies in serum of experimentally-infected swine by immunochromatographic strip. Vet Parasitol. 2013;194(2-4):125-127. doi:10.1016/j.vetpar.2013.01.036

18. Zhang G, Guo J, Wang X, et al. Development and evaluation of an immunochromatographic strip for trichinellosis detection. Vet Parasitol. 2006;137(3-4):286-293. doi:10.1016/j. vetpar.2006.01.026

19. Singh AV, Maharjan RS, Kanase A, et al. Machine-learning-based approach to decode the influence of nanomaterial properties on their interaction with cells. ACS Appl Mater Interfaces. 2021;13 (1):1943-1955. doi:10.1021/acsami.0c18470

20. Singh AV, Ansari M, Rosenkranz D, et al. Artificial intelligence and machine learning in computational nanotoxicology: unlocking and empowering nanomedicine. Adv Healthc Mater. 2020;9(17): e1901862. doi:10.1002/adhm.201901862

21. Duan H, Huang X, Shao Y, et al. Size-dependent immunochromatographic assay with quantum dot nanobeads for sensitive and quantitative detection of ochratoxin A in corn. Anal Chem. 2017;89 (13):7062-7068. doi:10.1021/acs.analchem.7b00869

22. Rong Z, Wang Q, Sun N, et al. Smartphone-based fluorescent lateral flow immunoassay platform for highly sensitive point-ofcare detection of Zika virus nonstructural protein 1. Anal Chim Acta. 2019;1055:140-147. doi:10.1016/j.aca.2018.12.043 
23. Wu Q, Wu P, Duan H, et al. Quantum dot bead-based immunochromatographic assay for the quantitative detection of triazophos. Food Agr Immunol. 2019;30(1):955-967. doi:10.1080/ 09540105.2019.1649638

24. Murrell KD, Pozio E. Worldwide occurrence and impact of human Trichinellosis, 1986-2009. Emerg Infect Dis. 2011;17 (12):2194-2202. doi:10.3201/eid1712.110896

25. Bruschi F, Gómez-Morales MA, Hill DE. International commission on Trichinellosis: recommendations on the use of serological tests for the detection of Trichinella infection in animals and humans. Food Waterborne Parasitol. 2019;14:e32. doi:10.1016/j.fawpar.2018. e00032

26. Gamble HR, Rapić D, Marinculić A, Murrell KD. Evaluation of excretory-secretory antigens for the serodiagnosis of swine trichinellosis. Vet Parasitol. 1988;30(2):131-137. doi:10.1016/03044017(88)90160-4

27. Gamble HR, Pozio E, Bruschi F, et al. International commission on trichinellosis: recommendations on the use of serological tests for the detection of Trichinella infection in animals and man. Parasite. 2004;11(1):3-13. doi:10.1051/parasite/20041113

28. Liu Y, Liu X, Li Y, et al. Evaluation of a cystatin-like protein of Trichinella spiralis for serodiagnosis and identification of immunodominant epitopes using monoclonal antibodies. Vet Parasitol. 2020:109127. doi:10.1016/j.vetpar.2020.109127.

29. Cooper HM, Paterson Y. Purification of immunoglobulin G fraction from antiserum, ascites fluid, or hybridoma supernatant. Curr Protoc Mol Biol. 2001;50:t11-t14. doi:10.1002/0471142727.mb1114s50
30. Gajadhar AA, Noeckler K, Boireau P, et al. International commission on Trichinellosis: recommendations for quality assurance in digestion testing programs for Trichinella. Food Waterborne Parasitol. 2019;16:e59. doi:10.1016/j.fawpar.2019.e00059

31. Singh AV. Commentary on "Peptide-Conjugated nanoparticles as targeted anti-angiogenesis therapeutic and diagnostic in cancer" by Shaker A. Mousa, Pharmaceutical Research Institute, Albany College of Pharmacy and Health Sciences, Rensselaer, NY 12144, United States - Peptide-Conjugated Nanoparticles for Multimodal Nanomedicine. Curr Med Chem. 2020;27(17):2927-2928. doi:10.2174/092986732717200604120627

32. Li Y, Zhou Y, Chen X, Huang X, Xiong Y. Comparison of three sample addition methods in competitive and sandwich colloidal gold immunochromatographic assay. Anal Chim Acta. 2020;1094:90-98. doi:10.1016/j.aca.2019.09.079

33. Mackay DK, Bulut AN, Rendle T, Davidson F, Ferris NP. A solid-phase competition ELISA for measuring antibody to foot-andmouth disease virus. J Virol Methods. 2001;97(1-2):33-48. doi:10.1016/s0166-0934(01)00333-0

34. Paiba GA, Anderson J, Paton DJ, et al. Validation of a foot-andmouth disease antibody screening solid-phase competition ELISA (SPCE). J Virol Methods. 2004;115(2):145-158. doi:10.1016/j. jviromet.2003.09.016
International Journal of Nanomedicine

\section{Publish your work in this journal}

The International Journal of Nanomedicine is an international, peerreviewed journal focusing on the application of nanotechnology in diagnostics, therapeutics, and drug delivery systems throughout the biomedical field. This journal is indexed on PubMed Central, MedLine, CAS, SciSearch ${ }^{\mathbb{}}$, Current Contents ${ }^{\mathbb{R}} /$ Clinical Medicine,

\section{Dovepress}

Journal Citation Reports/Science Edition, EMBase, Scopus and the Elsevier Bibliographic databases. The manuscript management system is completely online and includes a very quick and fair peer-review system, which is all easy to use. Visit http://www.dovepress.com/ testimonials.php to read real quotes from published authors. 